\title{
Influence of Content and Diameter of Fibres and Chemical Treatment on the Dielectric Properties of Oil Palm Fibres - Rubber Composites
}

\author{
C. Santulli, M. Marzinotto, C. Mazzetti \\ Electrical Engineering Department - Università di Roma La Sapienza \\ via Eudossiana 18, 00184, Roma, Italy \\ S. Thomas \\ School of Polymer Science and Technology \\ Mahatma Gandhi University, Priyadarshini Hills P.O., Kottayam, Kerala, India
}

\begin{abstract}
In this work, the dielectric properties of oil palm fibres/rubber composite materials were characterised as regards fibre content (10, 20 and 30\% wt. fibres), fibre diameter and length (two types: macrofibres and microfibres) and treatment (three treatments: silane, benzoylation and added silica). Dielectric properties (loss factor, permittivity, dissipation factor, power loss density, AC conductivity) of all the composites and pure rubber were measured. The effect of fibre content was very evident in increasing the dielectric losses and the AC conductivity, while the effect of the type of fibres introduced was less evident. In contrast, a clear increase of the loss factor was obtained with benzoylated fibres, while the other treatments had a lesser influence on losses and AC conductivity.
\end{abstract}

\section{INTRODUCTION}

A dielectric material is a poor conductor of electricity, but an efficient supporter of electrostatic fields, used therefore in capacitors. Here, an increased relative permittivity (as defined in ASTM D150) allows the same charge to be stored with a smaller electric field, or via the application of a lower voltage. This leads to increased capacitance. Of course, the dielectric material, when charged, also absorbs electrical energy, which is termed as dielectric loss: losses need to be as low as possible in the service frequency of the capacitor.

Natural rubber, which is a dielectric material in competition with some polymer resins, such as polyethylene, has however higher losses, so that it is frequently doped with metal salts, such as zinc chloride and ammonium iodide /1/.

However, the interest in materials with more advantageous end-of-life scenarios, as assessed from Life Cycle Analysis (LCA) studies, brought back this material. It is also necessary to know whether the introduction of plant fibres in a natural rubber matrix can improve the dielectric properties, especially if limited chemical treatment is required to yield sufficient material properties for the envisaged application /2/. Plant fibre composites may in principle present an interest especially as multifunction materials, rather than pure dielectrics $/ 3 /$. In fact, the hollow cellular structure of plant fibres proves effective in providing insulation against heat and noise $/ 4 /$.

Some studies on the electrical properties of these materials suggested that the values of dielectric constant and volume resistivity in the material are somehow affected by the volume of reinforcement fibres introduced on dielectric constant $/ 5 /$. In particular, it has been noted that the dielectric constant progressively increases with fibre loading and decreases with higher frequency $/ 6 /$. 
In contrast, the effect of fibre treatment on dielectric properties has not yet been clearly assessed. It is noteworthy that treatment can be required to improve the mechanical and durability properties of natural fibres. and a number of treatments are available for this purpose $/ 7 /$.

In very recent years a quite large literature has been developed on oil palm fibre composites, whose use appears on the rise, as a component for agro-hybrid composites /8/. Knowing the effect of chemical and physical modifications on the dielectric properties of the material would in the long run imply supplying dielectric materials for electronic applications with an environmentally friendly end-of-life scenario. This can be considered an ambitious, albeit to be pursued, objective for studies such as the present one.

\section{EXPERINIENTAL}

\section{Materials}

Ten types of rubber compounds have been tested in this study, in the following simply referred to with numbers $I$ to 10. They are all natural rubber based compounds (cis-polyisoprene from Hevea Brasiliensis), whose compositions are reported in Table 1 , reinforced with fibres obtained from the leaves of oil palm (Elacis Guineensis), a plant originally' cropped in West Africa, but diffused also in some parts of India (Kerala), from where the fibres used in this study come. Oil palm macrofibres had a length of $6 \mathrm{~mm}$ and diameter in the region between 150 and $450 \mu \mathrm{m}$, after treatment, while the cellulose microfibrils extracted from oil palm fibres had a length of around 300-500 $\mu \mathrm{m}$ and diameter of 2-4 $\mu \mathrm{m}$, so that the aspect ratio was in the same range (about 15-40).

Table 1

Composition of the rubber composites tested in this study

\begin{tabular}{|c|c|}
\hline Sample & Material \\
\hline 1 & Pure natural rubber alone \\
\hline 2 & Natural rubber $+10 \%$ wt. oilpalm fibre macrofibres \\
\hline 3 & Natural rubber $+20 \%$ wt. oilpalm fibre macrofibres \\
\hline 4 & Natural rubber $+30 \%$ wt. oilpalm fibre macrofibres \\
\hline 5 & Natural rubber $+10 \%$ wt. microfibril \\
\hline 6 & Natural rubber $+20 \%$ wt. microfibril \\
\hline 7 & Natural rubber $+30 \%$ wt. microfibril \\
\hline 8 & Natural rubber $+30 \%$ wt. microfibril treated with silane \\
\hline 9 & Natural rubber $+30 \%$ wt. microfibril trated with benzoylation \\
\hline 10 & Natural rubber $+30 \%$ wt. microfibril with added $5 \mathrm{~g}$. of silica \\
\hline
\end{tabular}

The fibres were pretreated with $5 \% \mathrm{NaOH}$. Silane treatment was carried out by immersing the pretreated fibres in a 60:40 water/alcohol mixture, containing silane coupling agent, then washed in distilled water and dried. Benzoy lation was carried out by suspending the pretreated fibres in $10 \% \mathrm{NaOH}$ solution, and then and agitating them with benzoyl chloride. The isolated fibres were then soaked in ethanol to remove the untreated benzoyl chloride and finally were washed in distilled water and dried. More information on the above treatments is given in $/ 9 /$. 


\section{Dielectric measurements}

Samples in the form of $2.1 \mathrm{~mm}$ thickness foils have been used to perform the measurements of AC conductivity $\sigma_{u c}$ versus frequency in accordance with /10-11/. In Figure 1 the tubular electrode set-up (guarded, guards and unguarded electrodes) used for the measurements is reported. With the same set-up, the real and the imaginary parts of the dielectric constant, permittivity $\varepsilon$ ' and loss factor $\varepsilon$ ' have been also registered.

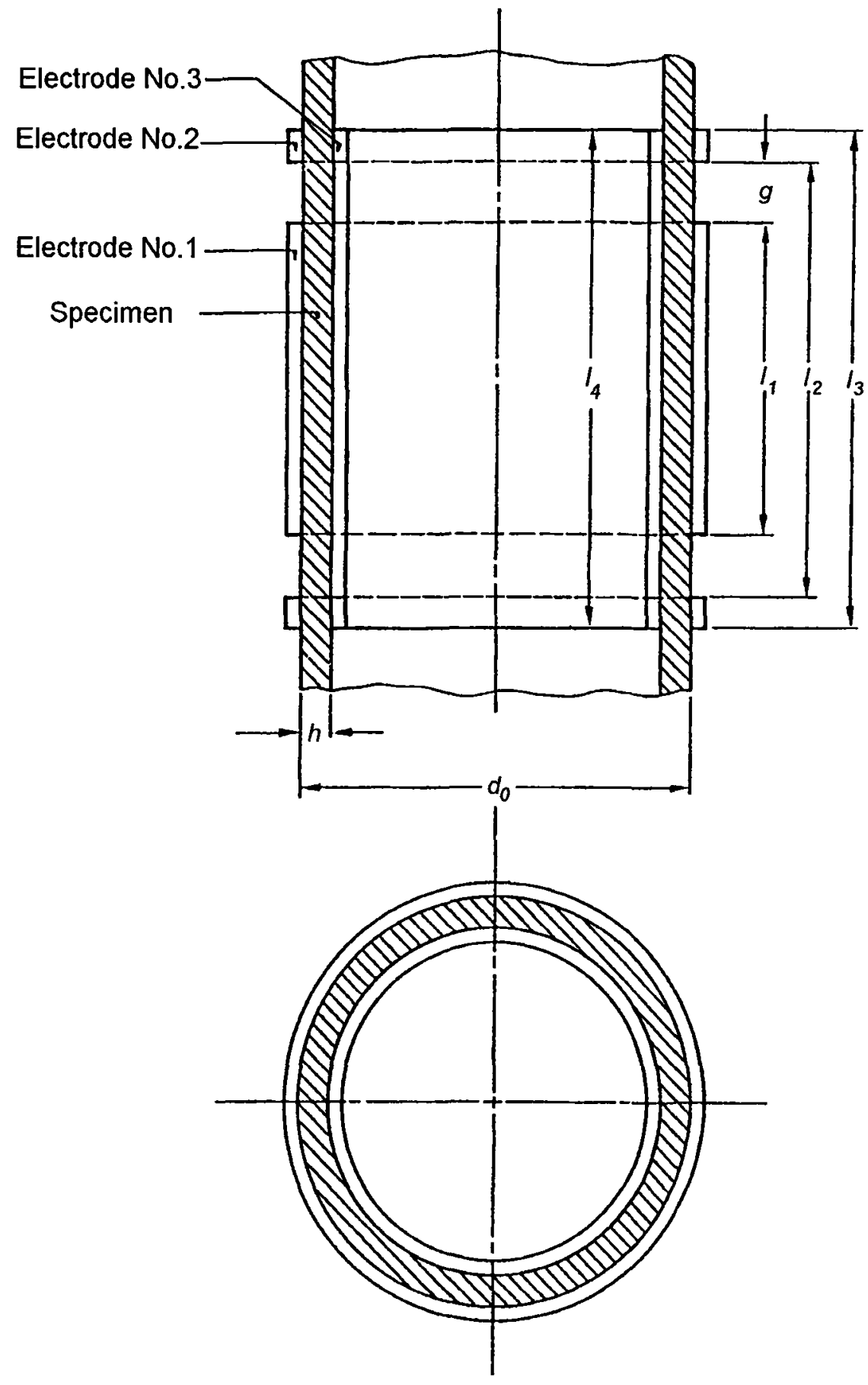

Fig. 1: Tubular electrode system used for the measurements (from $/ 7 /$ ).

Electrode no. 1: guarded electrode; electrode no. 2: guard electrode; electrode no. 3: unguarded clectrode. 
A digital RLC meter (50 Hz $\div 100 \mathrm{kHz}$ ) - Fluke PM6304 was used for the measurements of the above mentioned quantities. The measurements were performed applying a voltage of $2 \mathrm{~V}$ rms between the electrodes no. 1 (guarded clectrode) and electrode no. 3 (unguarded electrode) (Figure 1). Electrode no. 2 (guard electrode) was grounded $/ 10 /$.

Dissipation factor tan $\delta$ and power loss density $p_{a c}$ were calculated through the measurements of permittivity and loss factor as:

$$
\tan \delta=\frac{\varepsilon^{\prime \prime}}{\varepsilon^{\prime}}
$$

and

$$
p_{a c}=\frac{P_{a c}}{\psi}=\frac{\omega \cdot \varepsilon^{\prime \prime} \cdot C_{o}^{\prime} \cdot\left(E_{\max } \cdot r_{1} \cdot \ln \left(\frac{r_{2}}{r_{1}}\right)\right)^{2}}{\pi \cdot\left(r_{2}^{2}-r_{1}^{2}\right)}
$$

where

- $\omega$ is the angular frequency of the applicd voltage ( $2 \pi f)$;

- $C_{o}{ }^{\prime}$ is the capacity in per unit length between the electrodes (guarded and unguarded) without the samples $\left(\varepsilon_{\mathrm{r}}=1\right.$ );

- $E_{\max }$ is the electric field at the unguarded electrode (electrode no. 3 in Figure 1);

- $\Psi$ is the specimen volume in per unit length between electrodes 1 and 3 (Figure 1);

- $r_{1}$ is the inner radius of the electrode no. 3 (unguarded electrode);

- $r_{2}$ is the outer radius of the electrode no. 1 (guarded electrode).

The whole of the dielectric tests were performed at High Voltage Laboratory - Università La Sapienza - Roma.

\section{RESULTS}

This discussion of the results was aimed at clarifying a number of effects on the modification of a natural rubber dielectric material: the weight of oil palm macrofibres (comparison of sample 1 with samples 2, 3 and 4: Figures 2a-3a4a-5a) or microfibres (comparison of sample 1 with samples 5, 6 and 7: Figures $2 b-3 b-4 b-5 b-6 b$ ), and the effect of chemical treatment (comparison of sample 7 with samples 8, 9 and 10: Figures 2c-3c-4c-5c-6c).

The effect of the introduction of oil palm macrofibres was to reduce the permittivity at frequencies exceeding $1 \mathrm{kHz}$, a effect slightly more marked with an increasing amount of fibres, as can be observed in Figure 2a. In contrast, the introduction of microfibrils does increase the permittivity in the whole frequency range with respect to the pure rubber sample (Figure 2b). A further increase of permittivity is observed when treating the microfibrils, especially with silane.

From Figures 3, 4 and 5, referring to dielectric losses in terms of loss factor $\varepsilon$ ", dissipation factor tan $\delta$ and power loss density $p_{a c}$, it appears that both the introduction of macrofibres (Figures 3a-4a-5a) and the introduction of microfibrils (Figures $3 b-4 b-5 b$ ) have a very large effect of increasing the dielectric losses. Among the three treatments proposed, benzoylation contributed to further increase of losses, particularly observable from loss factor in Figure 3c, while the other treatments (silane, added silica) did not have a recognisable effect on losses (Figures 3c-4c-5c). For as regards AC conductivity $\sigma_{a c}$ values (Figure 6), the effect of the presence of oil palm fibres appears to prevail on both that of the amount of fibres introduced and on the effect of the treatments. In other words, the values measured for the non-pure rubber samples are much closer between them than with the pure rubber sample. In this way, even the introduction of the smallest amount of fibres (10\% wt.) increases the AC conductivity by at least an order of magnitude. 


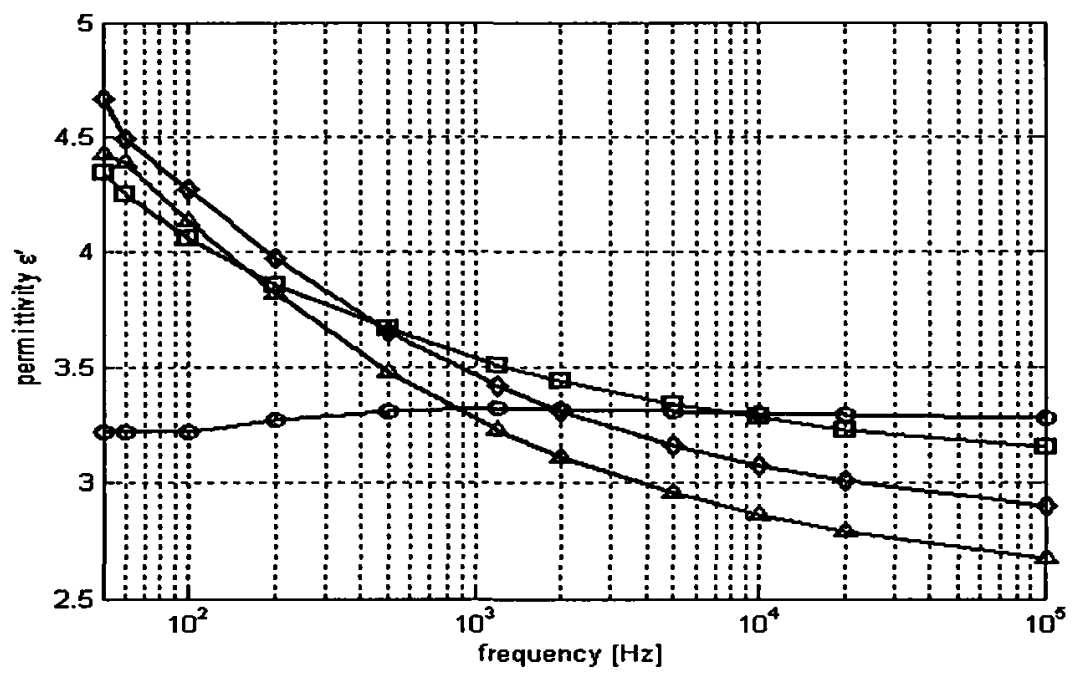

A

- Sample 1

口 Sample 2

- Sample 3

$\triangle$ Sample 4

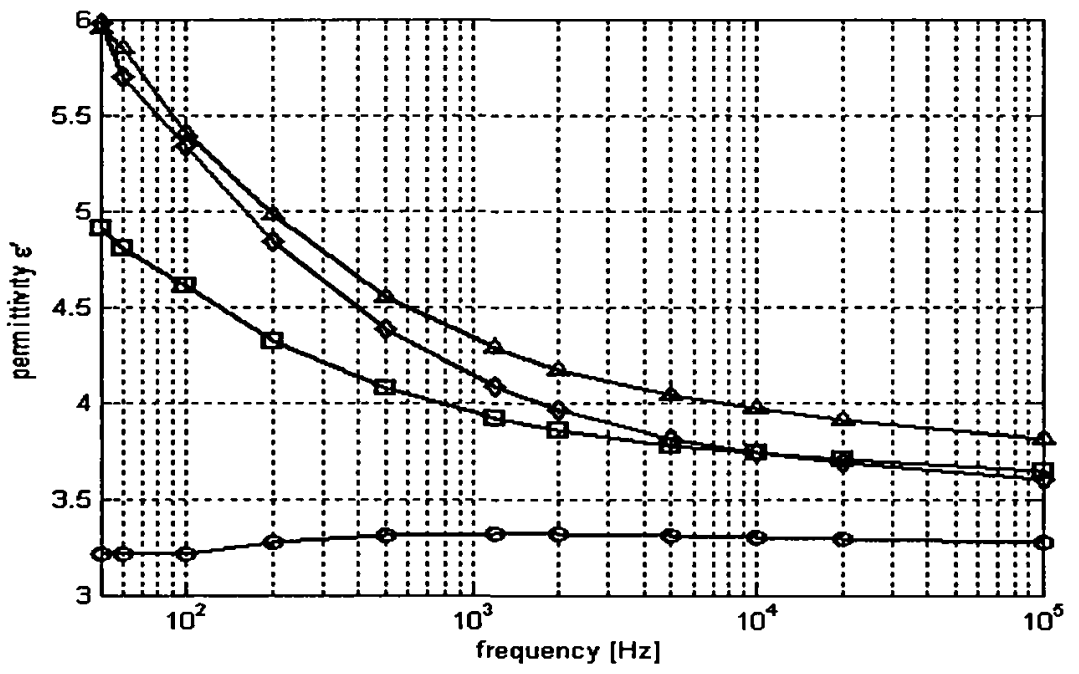

- Sample 1

a Sample 5

- Sample 6

$\Delta$ Sample 7

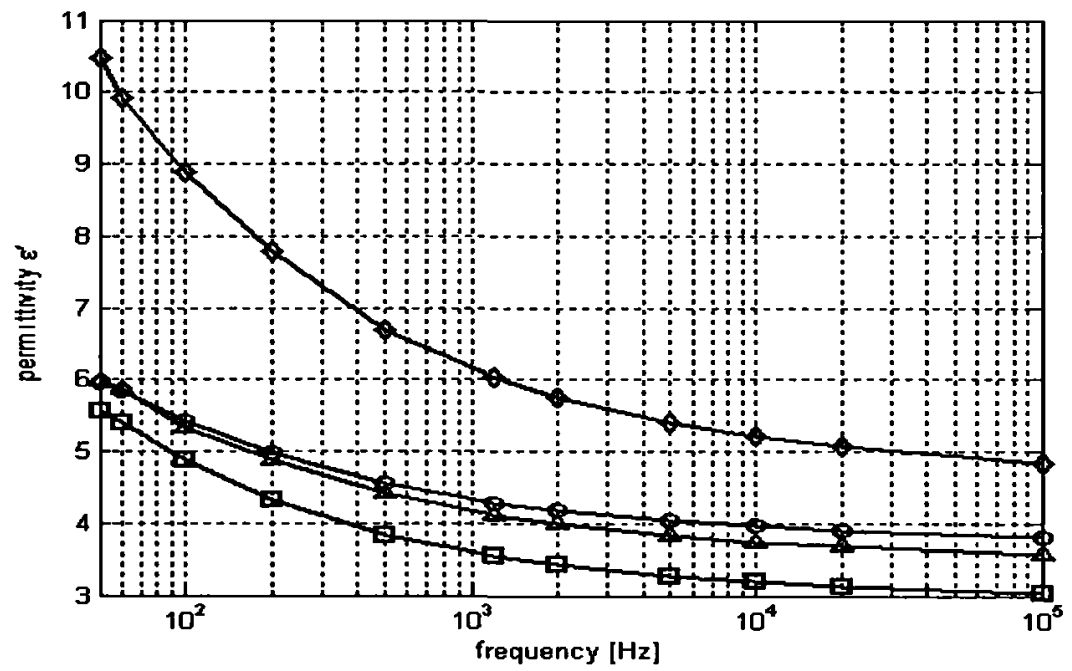

- Sample 7

口 Somple 8

- Sample 9

$\Delta$ Sample 10

Fig. 2: Permittivity $\varepsilon$ 'vs. frequency curves 

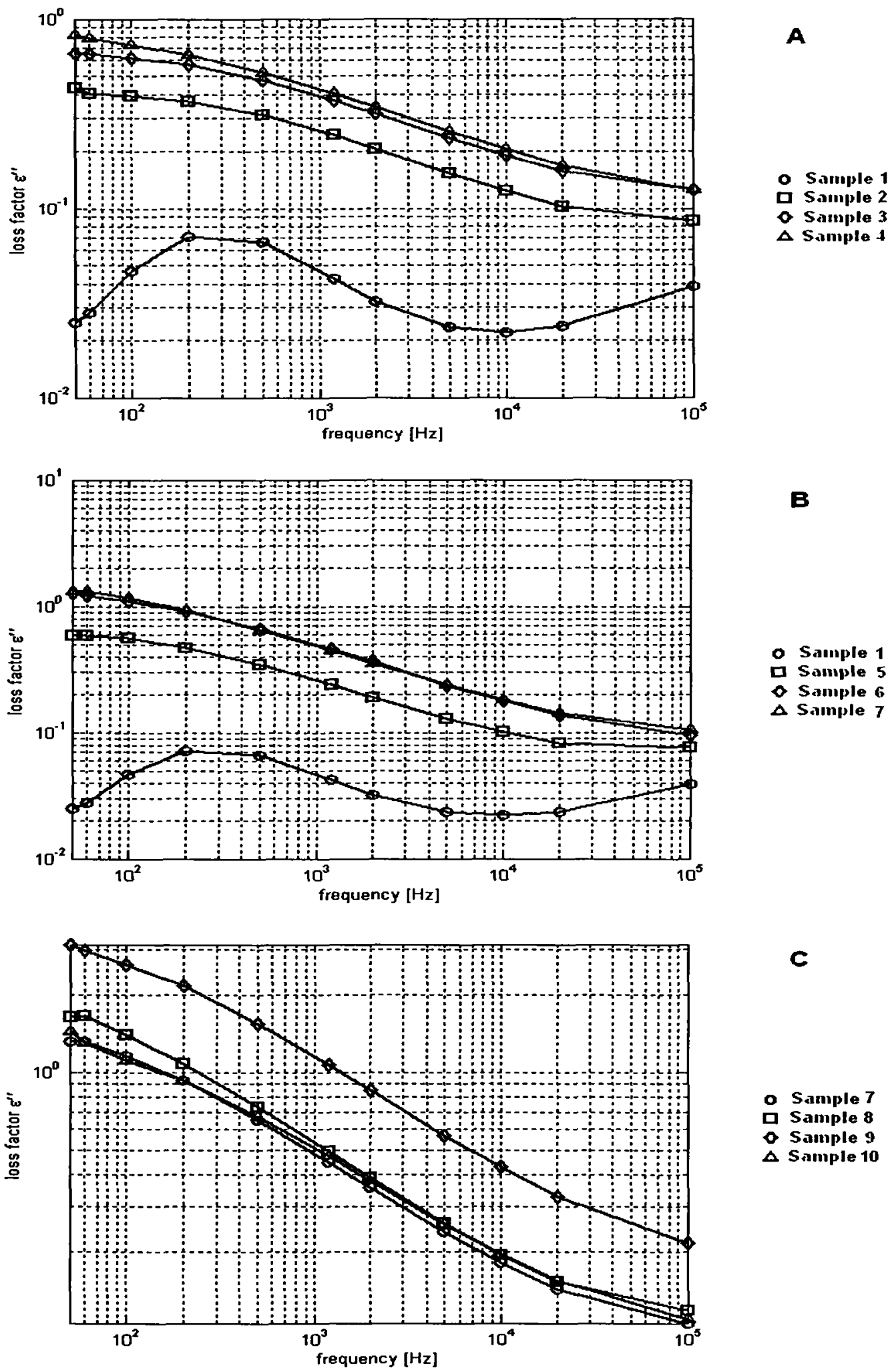

- Sample 7
口 Sample 8
o Sample 9
A Sample 10

Fig. 3: Loss factor $\varepsilon^{\prime \prime}$ vs. frequency curves 


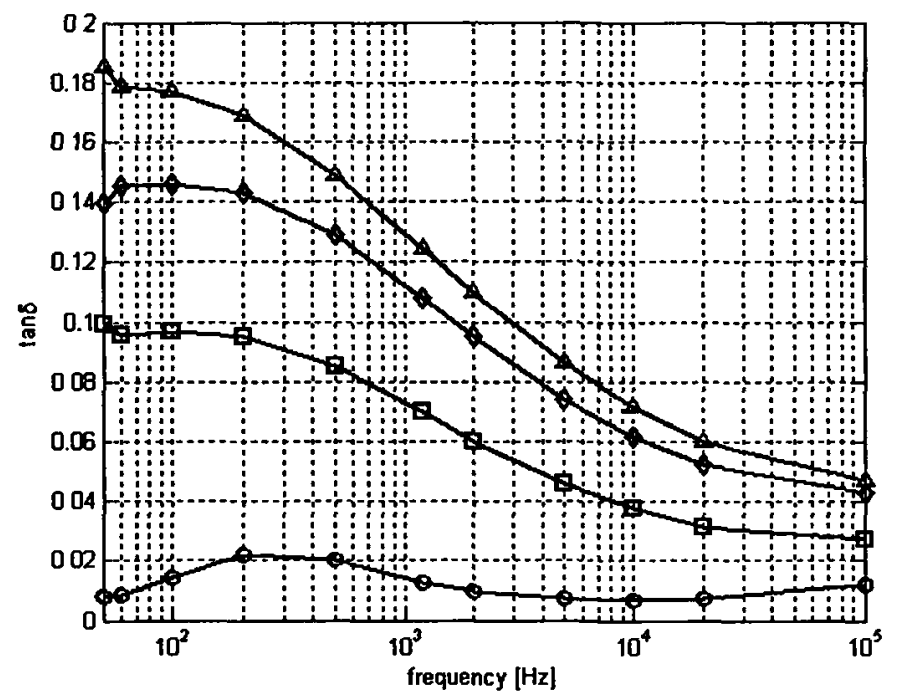

A

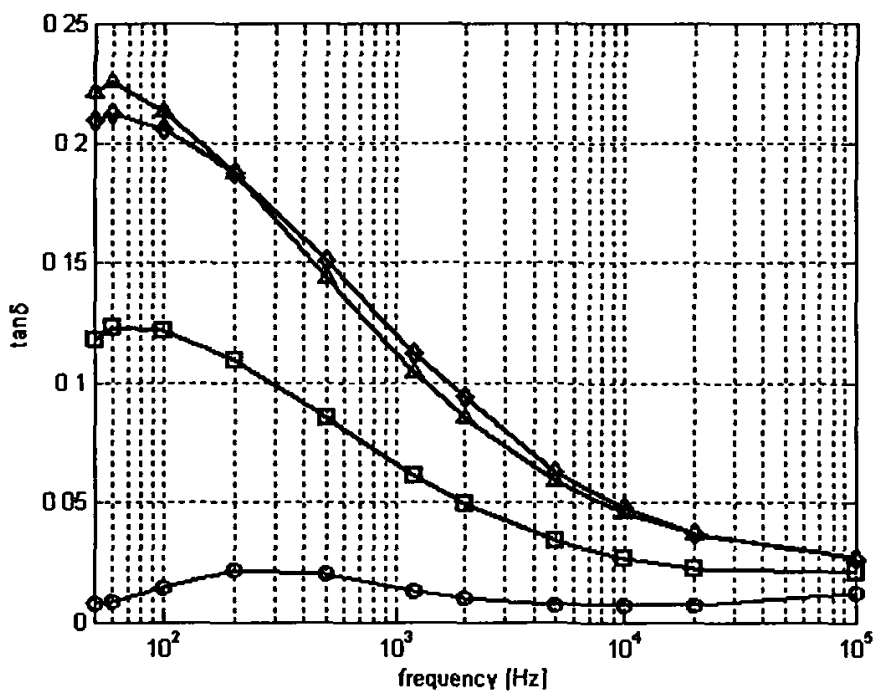

- Sample 1

d Sample 2

- Sample 3

$\triangle$ Sample f

- Sample 1

c Sample 5

- Sample 6

$\Delta$ Sample 7

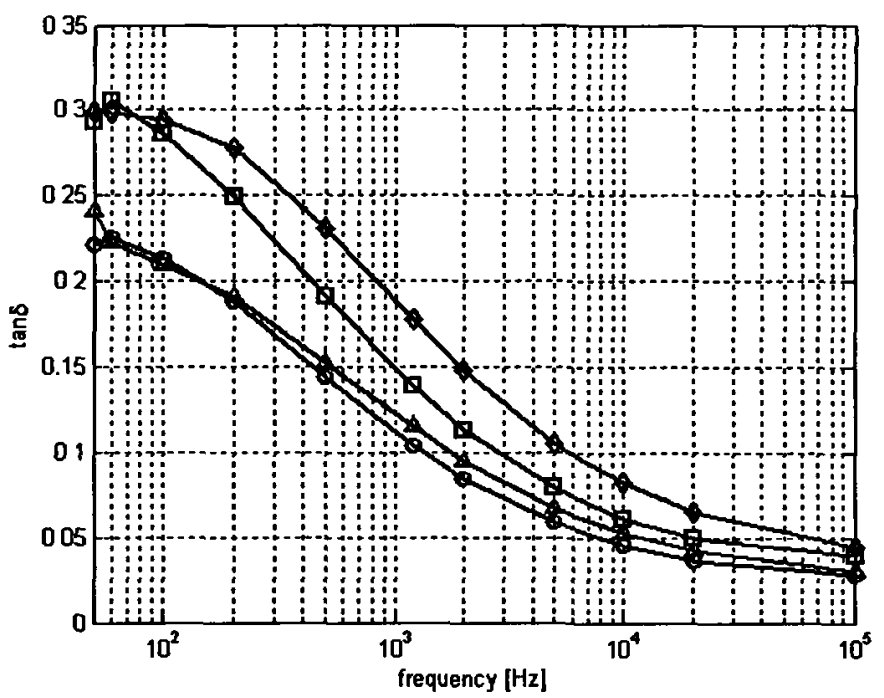

- Sample 7

- Sample 8

- Sample 9

$\triangle$ Sample 10

Fig. 4: Dissipation factor $\tan \delta$ vs. frequency curves 


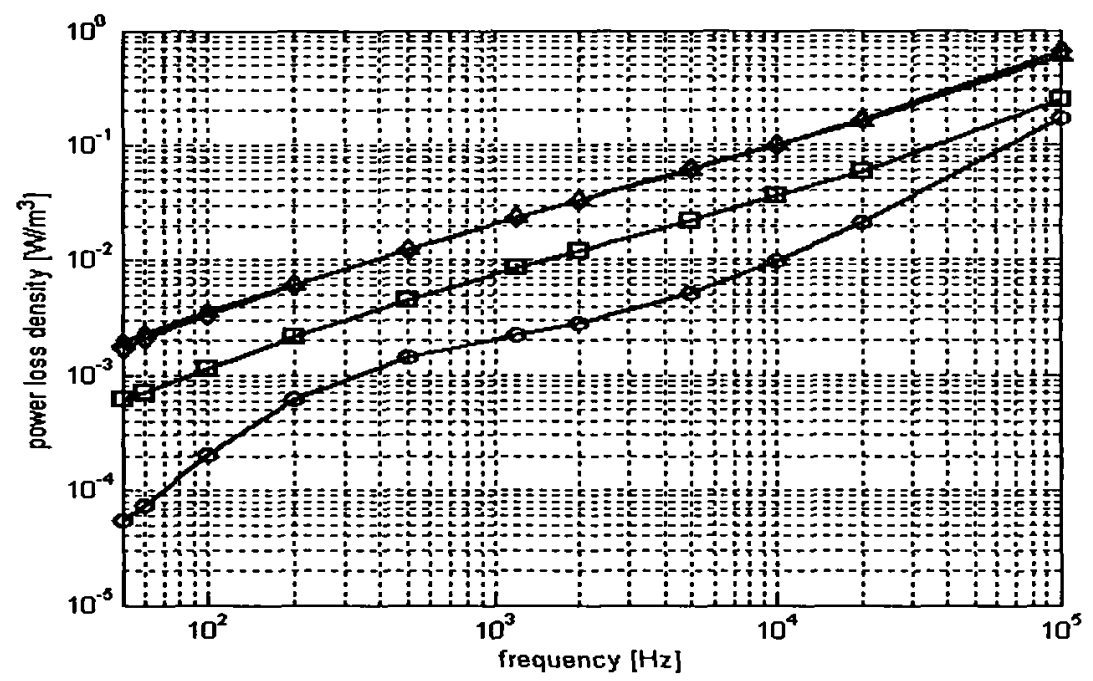

A
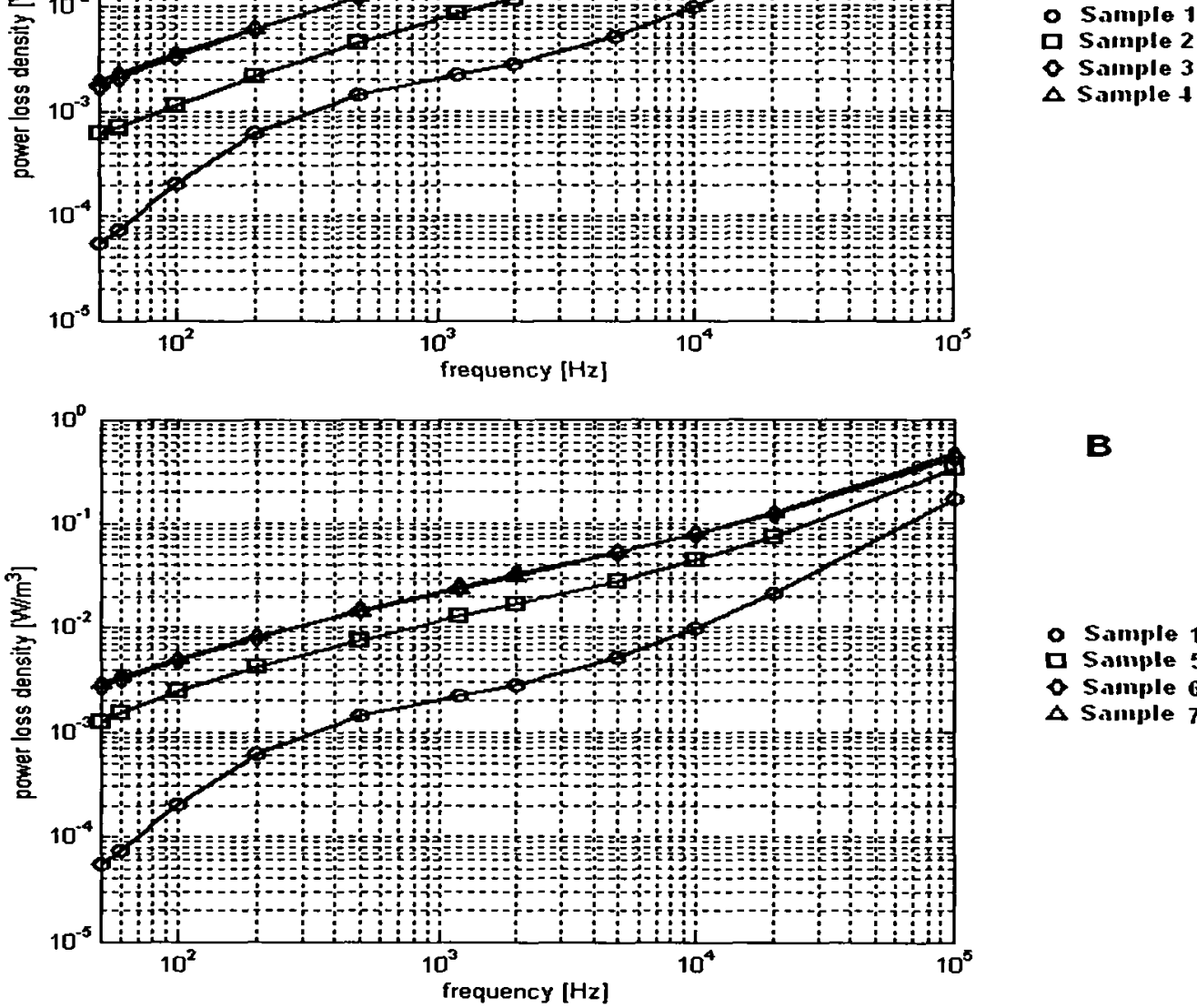

- Sample 1

口 Sample 5

- Sample 6

$\triangle$ Sample 7

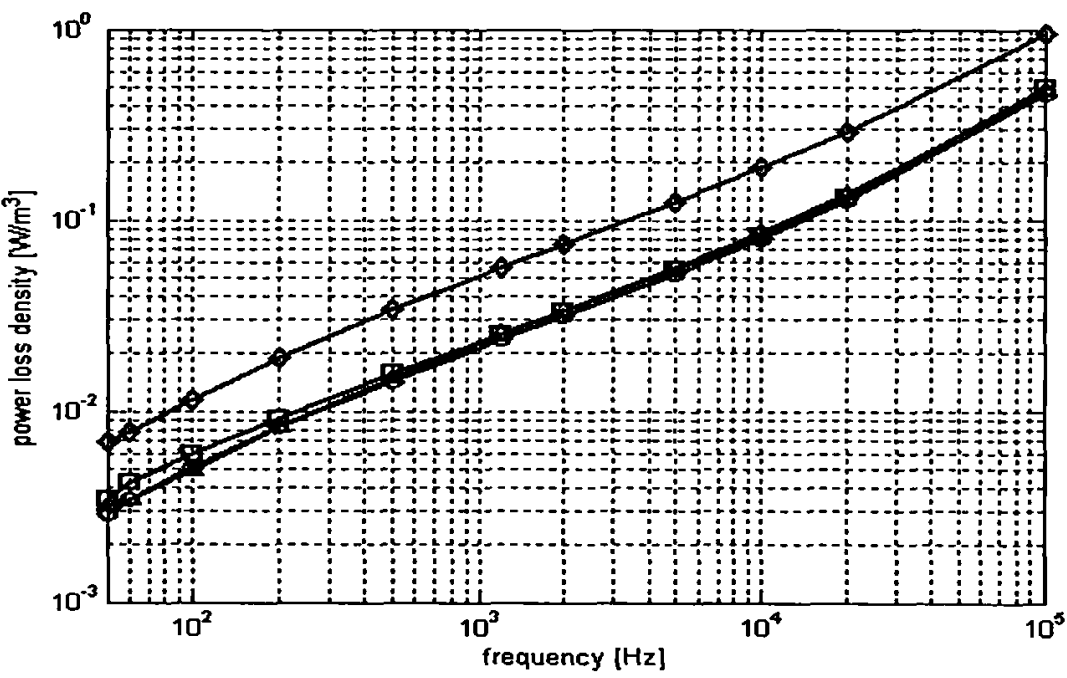

- Sample 7

口 Sample 8

- Sample 9

$\triangle$ Sample 10

Fig. 5: Power loss density $p_{a c}$ vs. frequency curves 


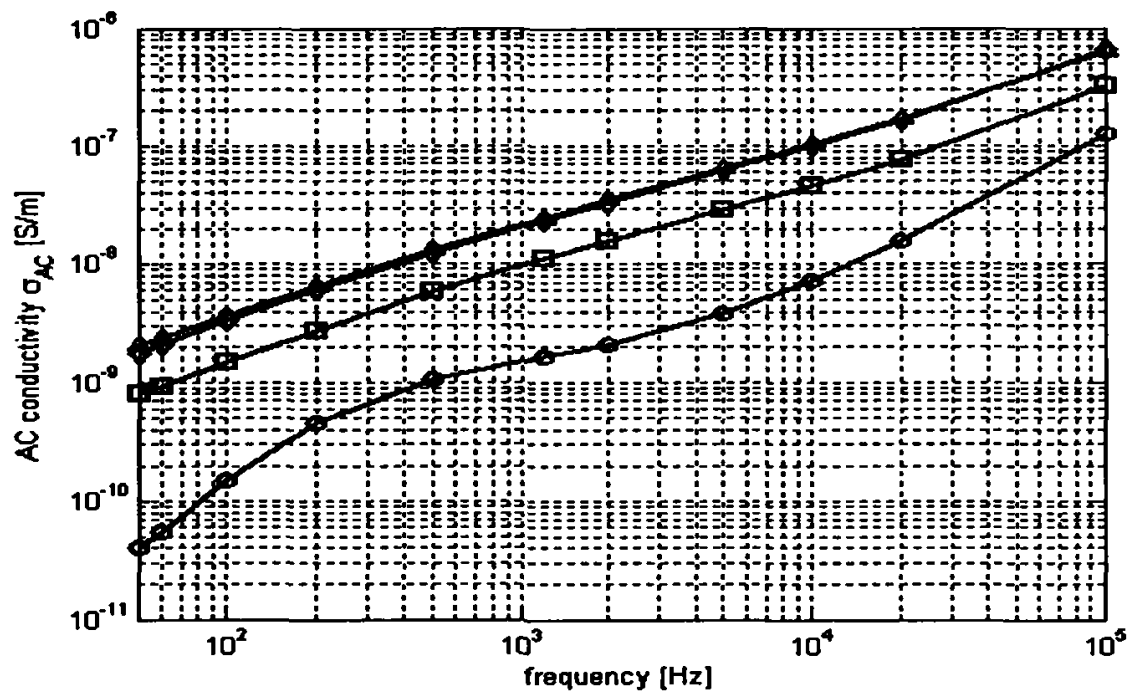

A

- Sample 1

- Sample 2

- Sample 3

$\triangle$ Sample 4

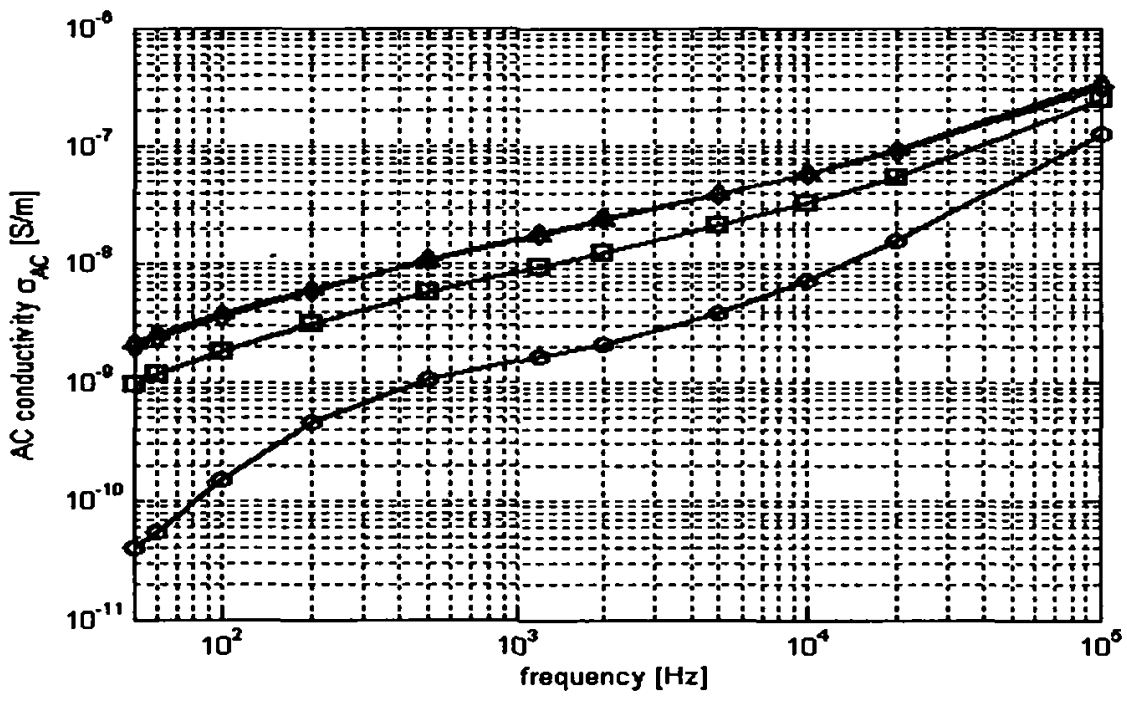

- Sample 1

- Sample 5

- Sample 6

$\Delta$ Sample 7

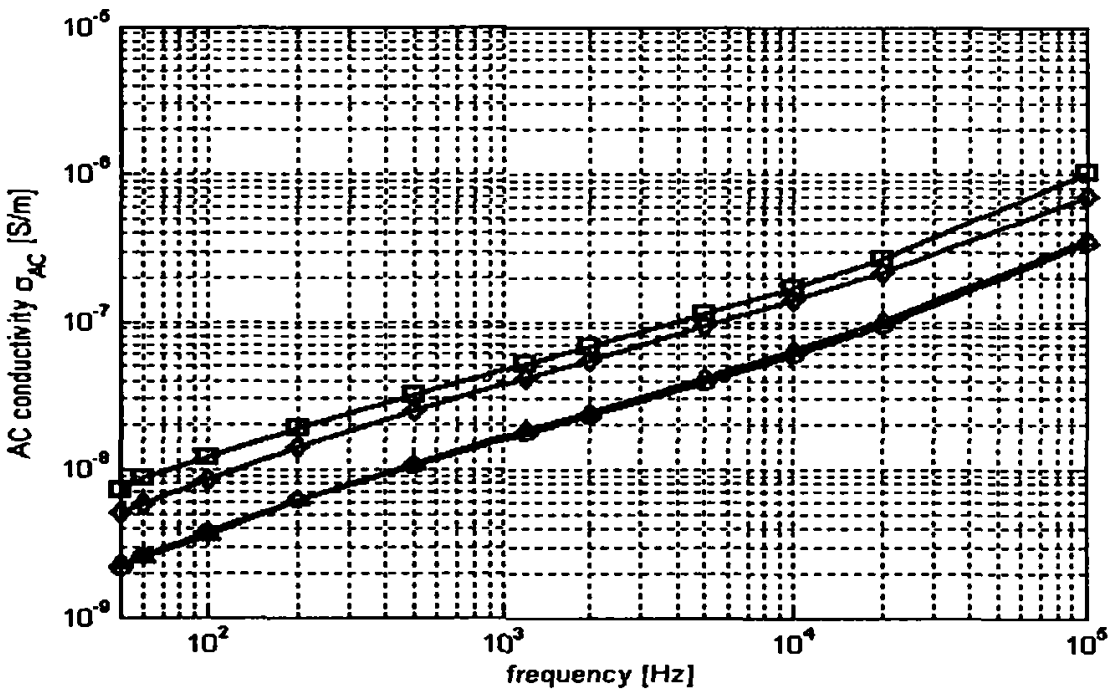

- Sample 7

D Sample 8

- Sample 9

A Sample 10

Fig. 6: AC conductivity $\sigma_{a c}$ vs. frequency curves 
A second possible effect is that of water absorption in the samples, which can be predicted to increase the conductivity of the samples /13/. It is also possible to suggest that treated fibres, having a better sizing with lesser defects, absorb less water and therefore have reduced losses with respect to the same material with the same amount of untreated fibres $/ 14 /$.

Here below, some explanation is attempted of the results obtained. A major difficulty in evaluating the dielectric propertics of materials including plant fibres is that these strongly depend on fibre orientation, as suggested in /12/ for sisal fibre reinforced composites. The fibres considered in the present study were inserted with statistical random orientation and therefore there might be non negligible variations of the dielectric properties from region to region of the materials on study, depending on the local orientation of fibres: the results presented can be described as average ones for the amount and geometry of fibres and treatment used in each case. The range of variation of dielectric properties would need the manufacture of samples with unidirectional fibre orientation and dispose them at different angle on the electrodes, which may be the objective of future work.

Other aspects remain uncovered, which may be treated in further studies: in particular, the amount of chemicals used for treatment may obviously increase the effect of reduced losses. In addition, the limited variation of the dielectric constant with respect to pure rubber observed in the material with the lower fibre content would suggest that the introduction of a very small amount of macrofibres (possibly less than $10 \%$ ) may virtually leave the dielectric properties unaffected, whilst still yielding some benefit in terms of lower cost and reduced environmental impact. This is a route which needs to be explored further too.

\section{CONCLUSIONS}

The effect of the introduction of oil palm fibres or of cellulose microfibrils and of their chemical treatment on the dielectric properties of pure rubber has been investigated, as a part of a study on the application of bio-composites in this field. Both the introduction of fibres and their chemical treatment resulted in a clear increase of permittivity and loss factors, an effect which was consistent in the whole frequency range, when microfibrils were introduced. More specifically, the introduction of microfibrils led to an consistent increase of permittivity (from 0.5 to 2 with respect to the value for the pure rubber) on the whole frequency range: this effect is enhanced by silane treatment. In contrast, the most effective fibre treatment to further increase dielectric losses in the composite proved to be benzoylation.

However, a number of other factors, such as e.g., fibre orientation and quantity of chemical used, are still to be assessed, which would be the object of further studies.

\section{ACKNOWLEDGMENT}

This work was supported in part by ISPESL (Istituto Superiore per la Prevenzione e la Sicurezza del Lavoro) Italian Focal Point in the information network of the European Agency for Safety and I Iealth at Work - www.ispesl.it.

\section{REFERENCES}

1. S.L. Abd-El Messieh, S. El-Sabbagh and I.F. Abadir, "Dielectric relaxation and mechanical investigation of ethylene propylene diene monomer rubber with some crosslinking additives", Journal of Applied Polymer Science 73, 1509-1519 (1999).

2. S.V. Joshi, L.T. Drzal, A.K. Mohanty and S. Arora, "Are natural fiber composites environmentally superior to 
glass fiber reinforced composites?" Composites A 35, 370-375 (2004).

3. C.K. Hong and R.P. Wool, "Low dielectric constant material from hollow fibres and plant oil", Journal of Natural Fibres 1, 83-92 (2004).

4. P. Kandachar and R. Brouwer, "Applications of bio-composites in industrial products", Materials Research Society Symposium-Proceedings, 2002.

5. M. Jacob, K.T. Varughese and S. Thomas, "Dielectric characteristics of sisal-oil palm hybrid biofibre reinforced natural rubber biocomposites", Journal of Materials Science 41, 5538-5547 (2006).

6. M. Jacob, S. Thomas and K.T. Varughese, "Mechanical properties of sisal/oil palm hybrid fibre reinforced natural rubber composites", Composites Science and Technology 64, 955-965 (2004).

7. A. Paul and S. Thomas, "Electrical properties of natural-fiber-reinforced low density polyethylene composites: A comparison with carbon black and glass-fiber filled low density polyethylene composites", Journal of Applied Polymer Science 63, 247-266 (1997).

8. M. Khalid, C.T. Ratnam, T.G. Chuah, A. Salmiaton and T.S.Y. Choong, "Comparative study of polypropylene composites reinforced with oil palm empty fruit bunch fiber and oil palm derived cellulose", Muterials \& Design, 29, 173-178 (2008).

9. X. Li, L.G. Tabil and S. Panigrahi, "Chemical treatments of natural fiber-reinforced composites: a review", Journal of Polymers and the Environment 15, 25-33 (2007).

10. IEC 60093, "Methods of test for volume resistivity and surface resistivity of solid electrical insulating materials", 1980.

11. M. Lisowski and R. Kacprzyk. "Changes proposed for the IEC 60093 Standard concerning measurements of the volume and surface resistivities of electrical insulating materials", IEEE Transactions on Dielectrics and Electrical Insulation 13, 139-145 (2006).

12. N. Chand and D. Jain. "Effect of sisal fibre orientation on electrical properties of sisal fibre reinforced epoxy composites", Composites Part A36, 594-602 (2005).

13. A.N. Fraga, E. Frulloni, O. de la Osa, J.M. Kenny and $\Lambda$. Vazquez, "Relationship between water absorption and dielectric behaviour of natural fibre composite materials", Polymer Testing 25, 181-187 (2006).

14. V.P. Cyras, C. Vallo, J.M. Kenny and A. Vazquez, "Effect of chemical treatment on the mechanical properties of starch-based blends reinforced with sisal fibre", Journal of Composite Materials 38, 1387-1399 (2004). 
